\title{
Compressive Mechanical Properties and Micromechanical Characteristics of Warm and Ice-Rich Frozen Silt
}

\author{
Yugui Yang, ${ }^{1,2}$ Feng Gao, ${ }^{2}$ and Yuanming Lai $^{3}$ \\ ${ }^{1}$ State Key Laboratory for Geomechanics and Deep Underground Engineering, China University of Mining and Technology, \\ Xuzhou, Jiangsu 221008, China \\ ${ }^{2}$ School of Mechanics and Civil Engineering, China University of Mining and Technology, Jiangsu 221116, China \\ ${ }^{3}$ State Key Laboratory of Frozen Soil Engineering, Cold and Arid Regions Environmental and Engineering Research Institute, \\ Chinese Academy of Sciences, Lanzhou 730000, China
}

Correspondence should be addressed to Yugui Yang; ygyang2009@126.com

Received 26 September 2014; Accepted 26 November 2014

Academic Editor: Xing Chen

Copyright (C) 2015 Yugui Yang et al. This is an open access article distributed under the Creative Commons Attribution License, which permits unrestricted use, distribution, and reproduction in any medium, provided the original work is properly cited.

It is recognized experimentally that the compressibility of warm and ice-rich frozen soil is remarkable under loading, which will cause a significant deformation and affect the stability of infrastructure constructed in cold region. In this paper, the real-time computerized tomography tests of warm and ice-rich frozen silt were carried out. The microstructure characteristics in the process of loading were studied, and the macromechanical behaviors were obtained at the same time. The test results showed that the stressstrain curve of warm and ice-rich frozen silt is sensitive to temperature; the peak stress was greatly enhanced with the decrease of temperature, and the section area increases with the increase of axial strain; the water content mainly decreases with the increase of axial strain at $-1^{\circ} \mathrm{C}$; the change of water content is not obvious at $-2^{\circ} \mathrm{C}$ in the loading process. The density damage changes little at first and then increases with the further increase of axial strain.

\section{Introduction}

About 20\% continental land in China is covered by permafrost. In permafrost regions, mechanical properties have been one of the most extensively studied aspects in many engineering problems. The mechanical behavior of frozen soil is crucial to the stability of construction of embankment engineering, such as highways, railways, and other engineering activities in permafrost regions [1-5]. Moreover, with the climate getting warm, the engineering construction in permafrost regions will encounter a lot of problems in the embankment stability of warm and ice-rich frozen soil. Therefore in the evaluation of embankment stability in permafrost regions, the possible influences of warm and ice-rich frozen soil have to be considered [6-8]. In order to explore the mechanical properties of frozen soil and make the design of frozen soil engineering more scientific and reasonable, a series of studies in warm and ice-rich frozen soils have been carried out. Considering the effect of water contents and temperature, [6] studied the strength characteristic of warm and ice-rich frozen clay by carrying out uniaxial compression test. The test results indicated that the type of stress-strain curves of warm and ice-rich frozen clays is strain-hardening, and the form of sample failure is plastic. Reference [9] carried out experimental studies on the compressible behavior of warm and ice-rich frozen clay and found that the frozen clay is essentially sensitive to both load and temperature. Reference [10] studied the dynamic strength characteristic of ice-rich frozen clay under various temperatures and confining pressures. The creep behaviors of warm and ice-rich frozen soils were also studied by researchers. Reference [11] investigated uniaxial creep tests of frozen clay with various water contents $(40 \%, 80 \%$, and $120 \%)$ at warm temperature $\left(-0.3^{\circ} \mathrm{C},-0.5^{\circ} \mathrm{C}\right.$, and $\left.-1.0^{\circ} \mathrm{C}\right)$ and found that the strain rate decreased with the increasing in time. Reference [12] carried out a series of investigations on the creep deformation of warm and ice-rich frozen clay with various water contents at different temperatures.

The studies mentioned above are the latest developments in warm and ice-rich frozen silt. It can be seen that the macromechanical characteristic of warm and ice-rich frozen has been acquired; however, there are few studies concerning 
the micromechanical characteristic of warm and ice-rich frozen soil. The mechanical properties of frozen soil are essentially governed by the constituent grains' properties and their structures. The microstructure of ice-rich frozen soil is shown in Figure 1.

Grain properties include its size, shape, crushability, and so on, while the frozen soil structure can be represented by void ratio, fabric tensor, the orientation of grain's axes, and so on. It is necessary to know both the macromechanical property and the microstructure evolution of frozen soils during deformation process. Recent development of computer ability has made it possible to handle such microscopic properties. The development of noninvasive imaging allied with computed tomography has begun to allow the study of inner structure propagation of frozen soil and the measurement of localized change of water content. CT is a quantitative measurement technology based on digital techniques, which is used to detect and describe the sectional characteristics of tested materials, and has been applied to investigations of frozen soil [13].

In order to explore the deformation and failure behavior of warm and ice-rich frozen soil, it is necessary to carry out the studies on micromechanical microstructure. In this paper, uniaxial compression tests of warm and ice-rich frozen silt were conducted, and the real-time computerized tomography tests of the microstructure propagation law in the whole deformation process have been completed. The stress-strain curve and CT image of cross section have been analyzed, and the area of cross section, volumetric water content, and density damage propagations are obtained. The results of this study may help elucidate why warm and ice-rich frozen soil is so subject to damage and displays such a contrasting temperature behavior, which is critical to designing possible solutions to reduce their damage in cold region engineering.

\section{Testing Method and Process}

2.1. Sample and Equipment. In this paper, the soil used in test was taken from Qinghai-Tibet Railway constructions' site and particle size distribution in Figure 2. The specimens were prepared as cylinders with $6.18 \mathrm{~cm}$ in diameter and $12.5 \mathrm{~cm}$ in height. The water content and the average dry density of the specimens tested were $40.0 \%$ and $1.43 \mathrm{~g} / \mathrm{cm}^{3}$, respectively. The preparations of specimens had been given a detailed introduction by [14]. After the preparation of the specimen ends, the specimen was placed into the loading equipment.

The computerized tomography equipment adopted in this study is the spiral scanning Siemens SOMATOM-PLUS $\mathrm{X}$-ray (see Figure 3 ). This test system includes 4 parts: the cooling bath cyclic system, the loading system, computerized tomography machine, and data acquisition system. The special loading apparatus is winded with cold bathing pipes. The alcohol is used as the cold bath medium. The range of temperature for the digital temperature control system is $-20 \sim 25^{\circ} \mathrm{C}$ and we had a temperature accuracy of $\pm 0.1^{\circ} \mathrm{C}$.

2.2. Test Method and Process. After the specimens were placed into the loading equipment, the loading equipment was wrapped with foam rubber sponge, which was used

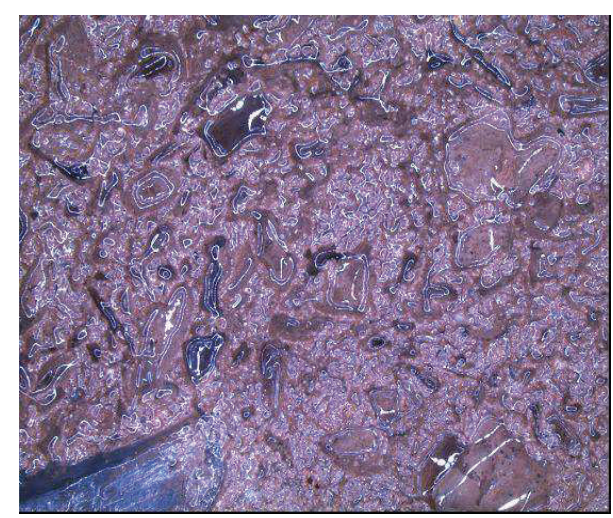

FIGURE 1: The electron microscope scanning image.

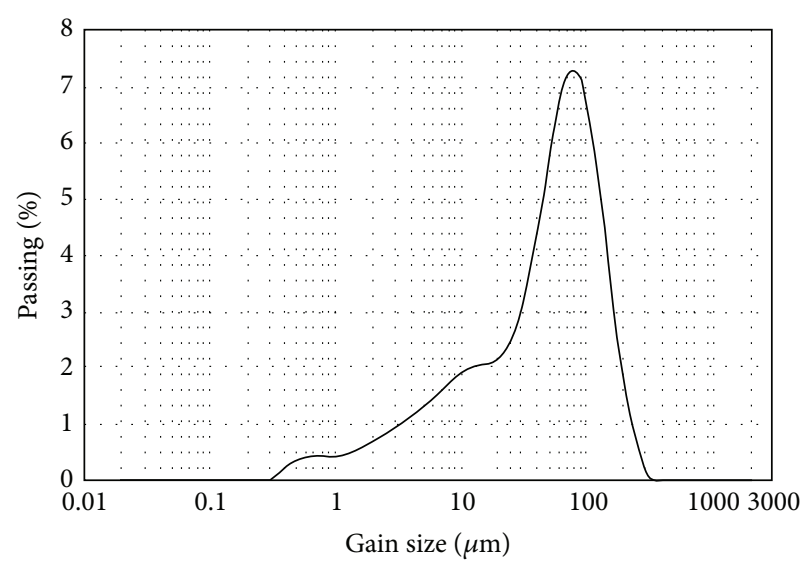

FIgURE 2: Particle size distribution of silt.

to keep the temperature stability of loading apparatus and frozen soil. Then, the temperature was adjusted to the specified temperature by the digital temperature control system. The sample was loaded at a rate of $0.3 \mathrm{~mm} / \mathrm{min}$. When the axial strains were $0,1,3,6,10$, and $15 \%$, the specimen location was adjusted to proper scanning stratum position, as shown in Figure 4; then it was scanned by the computerized tomography method at specific horizon of sample of frozen soil. The force value, section area, and CT value were recorded by the computer system which corresponds to the loading system.

\section{Analysis of the Test Results}

We review observations on behavior in the elastoplastic deformation that throw light on the evolution of microstructure and thus on the mechanism of failure. We shall now be concerned with the complete progression of events as the whole stress-strain or force-displacement curve. The stress is computed by taking the average of all forces and dividing by appropriate areas. The strain in the axial direction is computed using the current specimen length and the original specimen length. In order to accurately study the stress-strain characteristic of warm and ice-rich frozen silt, the section area evolution of frozen soil sample should be researched. The cross section deformation subjected to loading is studied using CT scanning. From Figure 5, it can be seen that there is 


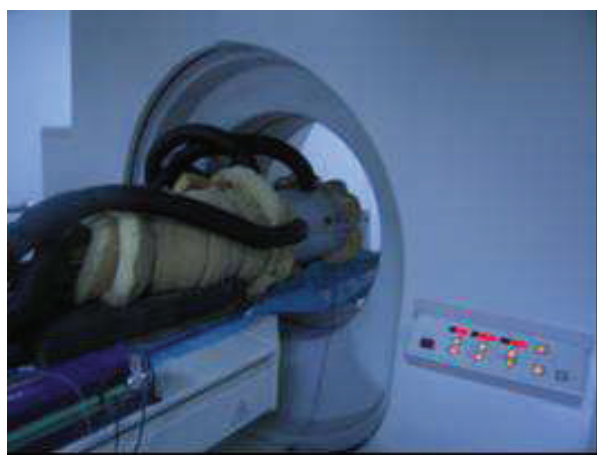

(a)

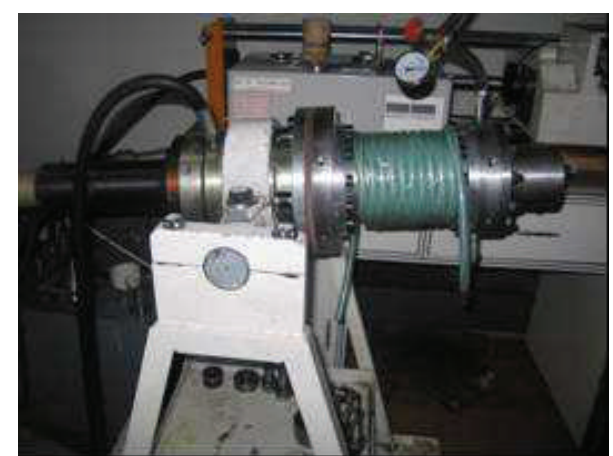

(b)

FIGURE 3: (a) The computerized tomography Siemens SOMATOM-PLUS X-ray and (b) the loading equipment matching of computerized tomography for frozen soil (after reference [15]).

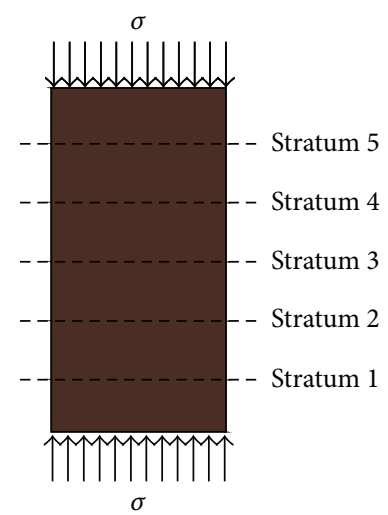

FIGURE 4: The scanning stratum positions of specimen.

a marked change in section area of warm and ice-rich frozen silt in the loading process. The section areas increase with the increase of axial strain. The maximum amount of cross section area increases about $20 \%$.

The stress-strain curves of warm and ice-rich frozen silt are shown in Figure 6 . It can be seen that there is significant difference between nominal stress and true stress in the compression process. The true stress is greatly larger than nominal stress with increasing in axial strain. The result also indicates that the calculation of stress should take the change of section area into account. The stress-strain behavior of warm and ice-rich frozen silt approximately experiences two stages: the initial linear elastic stage, where stress increases linearly with the increasing of axial strain, and there is little plastic strain in this stage, and the plastic stage, where the plastic deformation is dominating in the further loading process, and the elastic deformation is relatively subordinate.

The dry density and water content can reflect changes in the microstructure of the frozen silt associated with the deformation process that involves pores or microcrack. Inelastic density change is designated as dilation or compaction depending on whether there is volume increase or decrease, respectively. Warm and ice-rich frozen silt may be considered as elastoplastic material, of which the compressibility is remarkable under loading. Considering that the plastic material has no obvious crack in the loading process, the accurate damage propagation cannot be directly obtained from the visual image. The accurate damage propagation can be identified by the corresponding CT values of scanned slices. It is more significant to investigate the change of regularity of CT values in the loading process. The following equation shows the relationship between CT value and X-ray absorption coefficient of test material [16]:

$$
H=\frac{\mu-\mu_{W}}{\mu_{W}} \times 1000,
$$

where $\mu$ is the X-ray absorption coefficient per unit tested material mass; $\mu_{W}$ is the X-ray absorption coefficient of water. $H$ is the CT value of tested material.

The X-ray absorption law complies with addition principle. The X-ray absorption coefficient of frozen soil can be expressed as the following equation [16]:

$$
\mu=W_{V} \times \mu_{W}+\gamma_{d} \times \mu_{S},
$$

where $W_{V}$ is volumetric water content; $\gamma_{d}$ is dry density; $\mu_{W}$ and $\mu_{S}$ are the X-ray absorption coefficients of water and soil particle.

Table 1 contains the CT values of scanned slices corresponding to strains $0,1,3,6,10$, and $15 \%$. It is noted that the CT value of every scanned slice has certain regularities with the damage propagation of frozen silt. The CT values increase with increasing axial strain; with further increase of axial strain, the CT values decrease.

Figure 7 depicts the regularity of water content obtained from the seismic tomography. The water content of warm and ice-rich frozen silt at $-1^{\circ} \mathrm{C}$ decreases with the increase of axial strain at first; then the water content increases. With the further increase of axial strain, the water content decreases. The water content of warm and ice-rich frozen silt at $-2^{\circ} \mathrm{C}$ changes little in the loading process.

Figure 8 shows CT images of warm and ice-rich frozen silt. It is evident that the edge of specimen at $\varepsilon_{a}=0$ is slightly smooth; however, once the strain increases to $\varepsilon_{a}=$ $15 \%$, the edge becomes rough and has many burrs, which means that the structure of frozen soil has been damaged. 
TABLE 1: Distribution regularities of CT values of scanned slices.

\begin{tabular}{lcccc}
\hline Strain (\%) & $\begin{array}{c}\mathrm{CT} \text { value at }-1^{\circ} \mathrm{C} . \\
\text { Entire section area }\end{array}$ & $\begin{array}{c}\text { CT value at }-1^{\circ} \mathrm{C} . \\
\text { Major section area }\end{array}$ & $\begin{array}{c}\text { CT value at }-2^{\circ} \mathrm{C} . \\
\text { Entire section area }\end{array}$ & $\begin{array}{c}\mathrm{CT} \text { value at }-2^{\circ} \mathrm{C} . \\
\text { Major section area }\end{array}$ \\
\hline 0 & 1105.5 & 1223.2 & 1099.7 & 1219.5 \\
1 & 1105.7 & 1224.8 & 1100.7 & 1222.1 \\
3 & 1105.3 & 1226.6 & 1099.1 & 1223.0 \\
6 & 1103.8 & 1227.8 & 1097.6 & 1224.6 \\
10 & 1100.1 & 1226.0 & 1092.3 & 1221.8 \\
15 & 1092.7 & 1218.5 & 1083.2 & 1210.9 \\
\hline
\end{tabular}
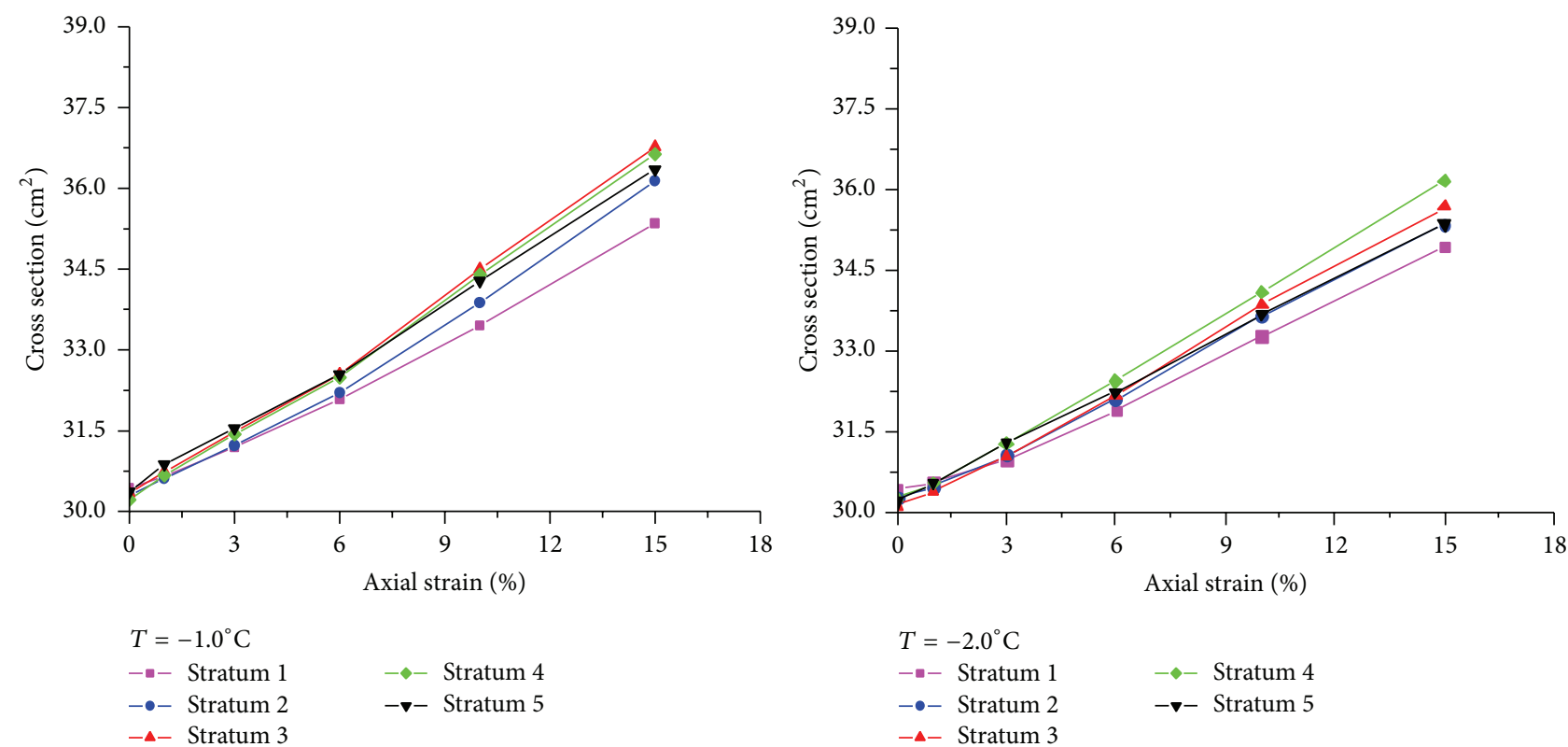

FIGURE 5: Cross section propagation of warm and ice-rich frozen silt.
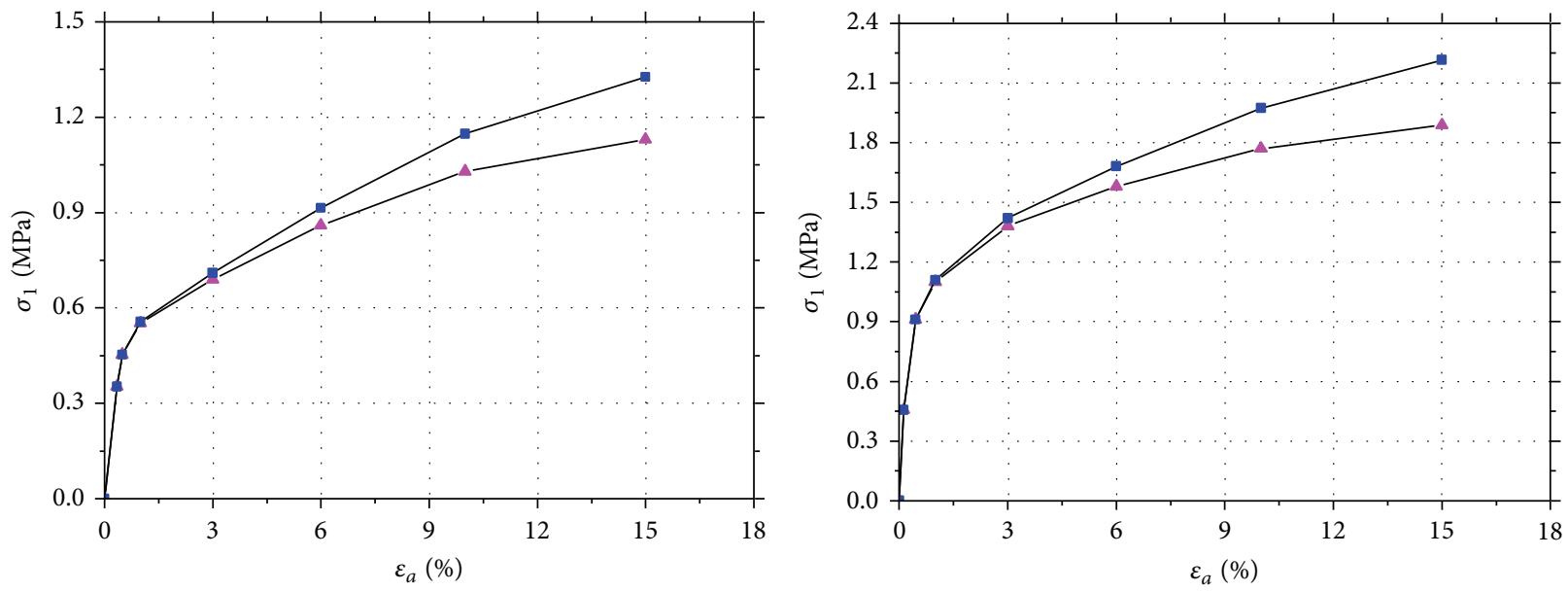

$$
\begin{aligned}
& T=-1.0^{\circ} \mathrm{C} \\
& -\triangle-\text { True stress } \\
& -- \text { Nominal stress }
\end{aligned}
$$

$$
\begin{aligned}
& T=-2.0^{\circ} \mathrm{C} \\
& -\triangle-\text { True stress } \\
& -- \text { Nominal stress }
\end{aligned}
$$

FIGURE 6: Stress-strain curves of warm and ice-rich frozen silt. 

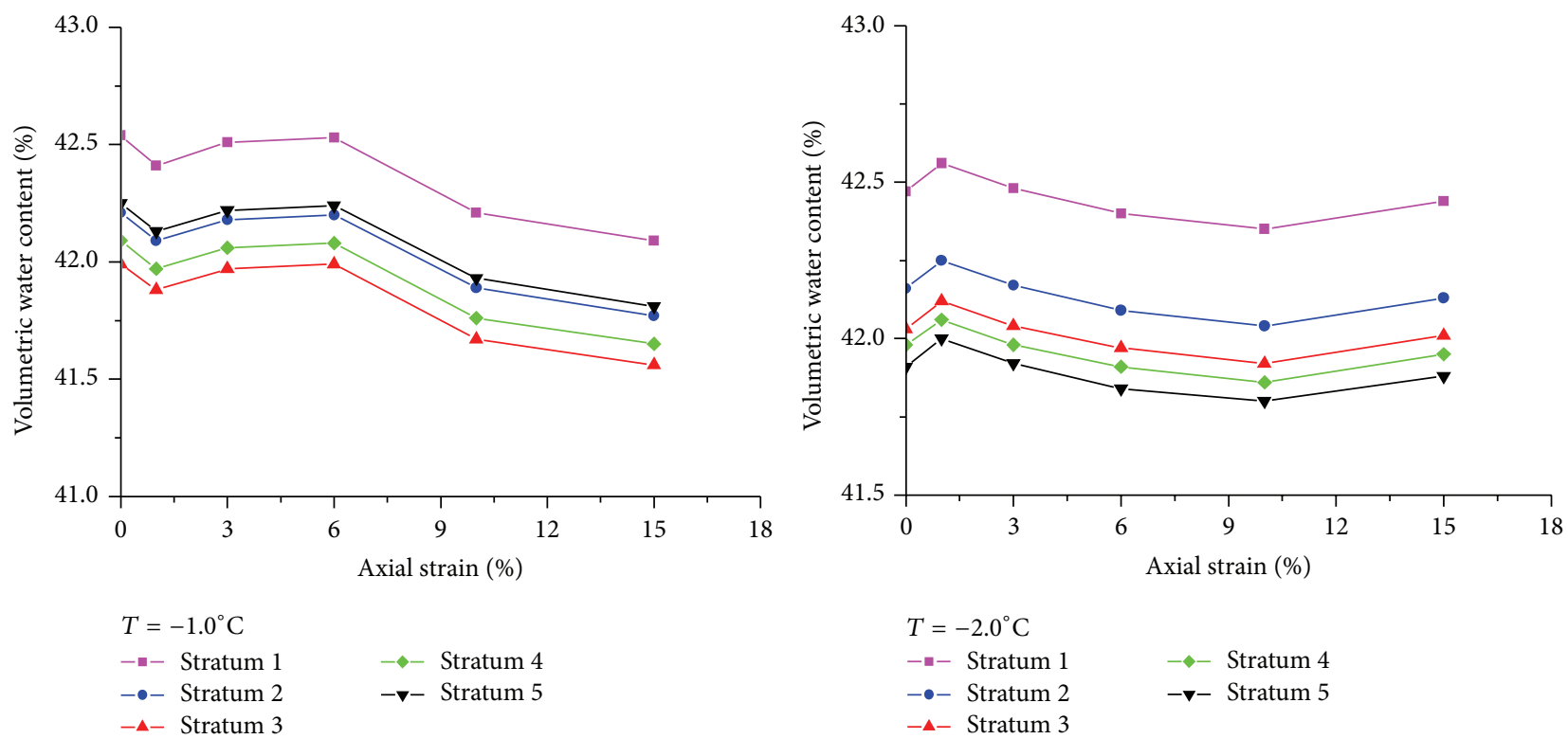

FIGURE 7: Distributions of volumetric water contents for warm and ice-rich frozen silt.
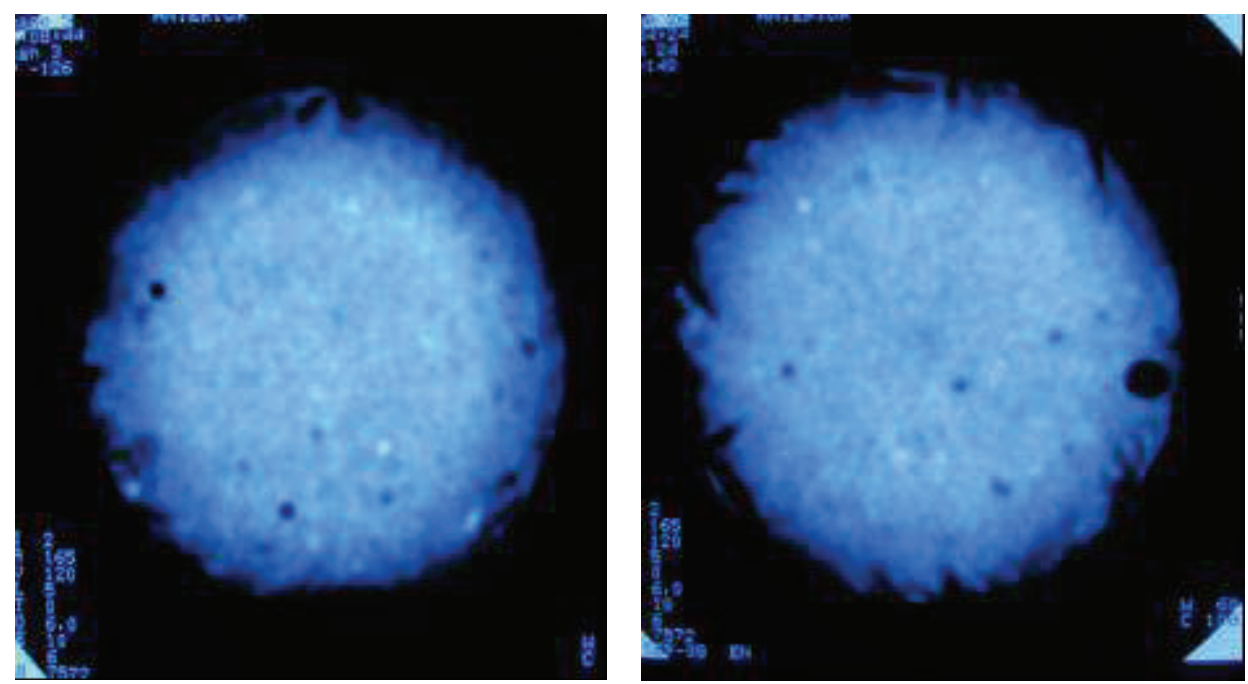

FIGURE 8: CT images with $\varepsilon_{a}=0$ and $\varepsilon_{a}=15 \%$ of warm and ice-rich frozen silt.

The visual observation of CT image cannot represent the accurate change of inner structure. In order to better describe propagation of inner structure, the density damage has been defined by the following equation [16]:

$$
\Omega=\left[1-\frac{\gamma_{d}}{2.8 \times\left(1-w_{v} \times B\right)}\right] \times 100 \%,
$$

in which $\gamma_{d}$ is the dry density of soil particle; $\gamma_{d}=2.8 \mathrm{~g} / \mathrm{cm}^{3}$; $w_{v}$ is volumetric water content; $B$ is expansion efficient.

Based on the analysis of water content, the density damage of warm and ice-rich frozen silt at various loading stages has been given in Figure 9.

The result shows that the initial density damage at different slices of sample is varying, but the change tendency is similar. Generally, the density damage changes little at first; then it increases with the further increase of axial strain. The nonlinear characteristic of density damage curve is obvious at $-1^{\circ} \mathrm{C}$; however, the damage curves show almost linear increase with increasing in axial strain at $-2^{\circ} \mathrm{C}$.

\section{Conclusions}

The nondestructive techniques computerized tomography is employed to assess the inner structure propagation of the warm and ice-rich frozen silt. The peak stress of warm and ice-rich frozen silt, which is sensitive to temperature, can be greatly enhanced with temperature decreasing from $-1^{\circ} \mathrm{C}$ to $-2^{\circ} \mathrm{C}$. The true stress of warm and ice-rich frozen silt is obviously larger than nominal stress, so the mechanical analysis of warm and ice-rich frozen soil should take the variation of section area into account. With the increase of 

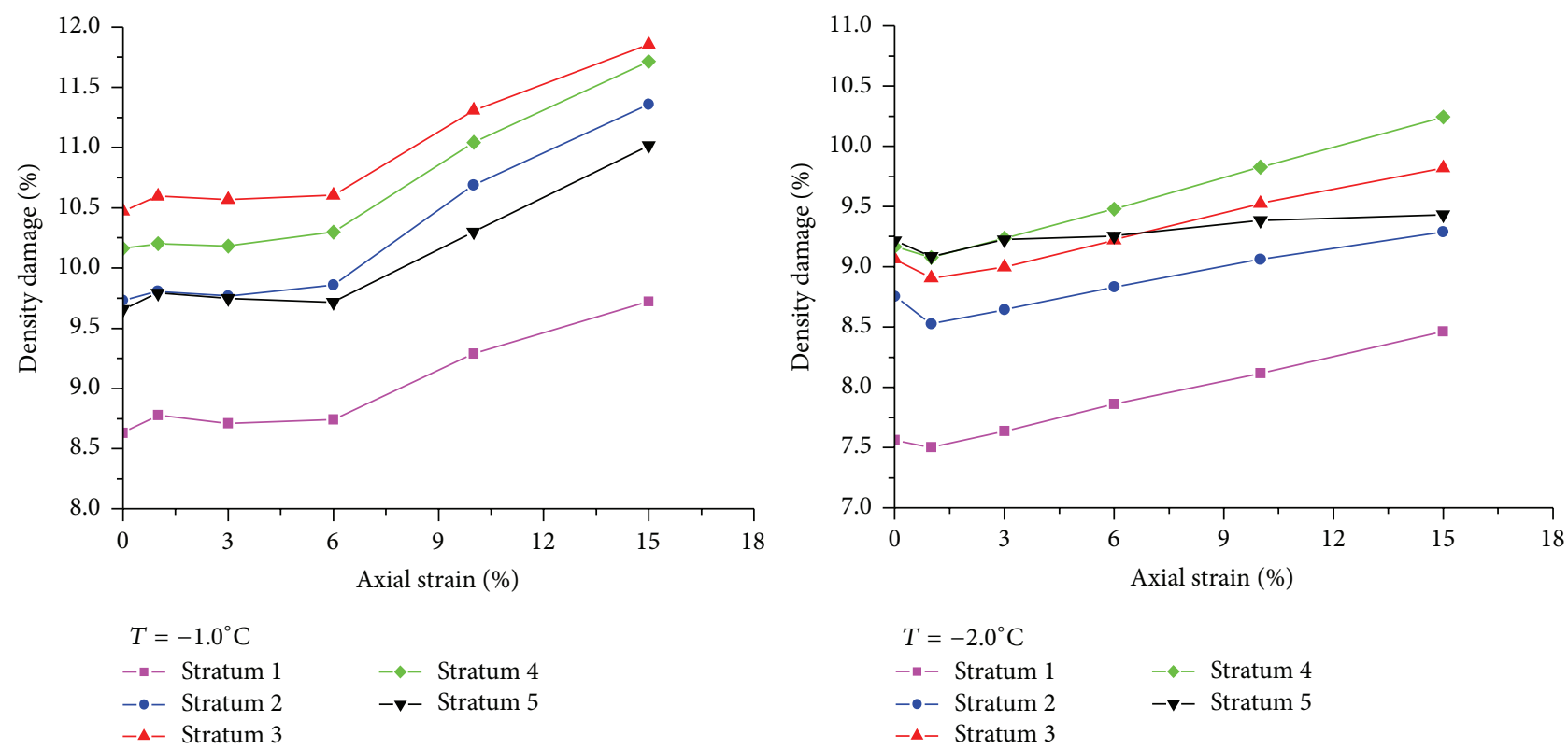

FIGURE 9: Distributions of density damage of warm and ice-rich frozen silt.

axial strain, the section area increases, and the maximum amount of cross section area increases about $20 \%$; the water content mainly decreases with the increase of axial strain at $-1^{\circ} \mathrm{C}$, and the change of water content is not obvious at $-2^{\circ} \mathrm{C}$ in the loading process. The density damage changes little at first; then it increases with the further increase of axial strain.

\section{Conflict of Interests}

The authors declare that there is no conflict of interests regarding the publication of this paper.

\section{Acknowledgments}

This research was supported by the National Natural Science Foundation of China (51204161) and the Fundamental Research Funds for the Central Universities (2012QNA57).

\section{References}

[1] V. R. Parameswaran and S. J. Jones, "Triaxial testing of frozen sand.", Journal of Glaciology, vol. 27, no. 95, pp. 147-155, 1981.

[2] A. M. Fish, "Strength of frozen soil under a combined stress state," in Proceedings of 6th International Symposium on Ground Freezing, vol. 1, pp. 135-145, A.A. Balkema, Rotterdam, The Netherlands, 1991.

[3] G. X. Cui, "Mechanics of frozen soil for deep alluvium- a new field of frozen soil mechanics," Journal of Glaciology and Geocryology, vol. 20, no. 2, pp. 97-100, 1998.

[4] W. Ma, G.-D. Cheng, Q.-B. Wu, and D.-Y. Wang, "Application on idea of dynamic design in Qinghai-Tibet Railway construction," Cold Regions Science and Technology, vol. 41, no. 3, pp. 165-173, 2005.

[5] Y. Lai, L. Jin, and X. Chang, "Yield criterion and elasto-plastic damage constitutive model for frozen sandy soil," International Journal of Plasticity, vol. 25, no. 6, pp. 1177-1205, 2009.
[6] W. Ma, G. Feng, Q. Wu, and J. Wu, "Analyses of temperature fields under the embankment with crushed-rock structures along the Qinghai-Tibet Railway," Cold Regions Science and Technology, vol. 53, no. 3, pp. 259-270, 2008.

[7] Y. Lai, S. Li, J. Qi, Z. Gao, and X. Chang, "Strength distributions of warm frozen clay and its stochastic damage constitutive model," Cold Regions Science and Technology, vol. 53, no. 2, pp. 200-215, 2008.

[8] S. W. Liu and J. M. Zhang, "Review on physic mechanical properties of warm frozen soil," Journal of Glaciology and Geocryology, vol. 34, no. 1, pp. 120-129, 2012.

[9] Y. H. Qin, J. M. Zhang, B. Zheng, and X. Ma, "Experimental study for the compressible behavior of warm and ice-rich frozen soil under the embankment of Qinghai-Tibet Railroad," Cold Regions Science and Technology, vol. 57, no. 2-3, pp. 148-153, 2009.

[10] Z. H. Gao, J. Shi, S. J. Zhang, and L. J. Luo, "Experimental study of the dynamic strength characteristics and residual strain of ice-rich frozen soil," Journal of Glaciology and Geocryology, vol. 31, no. 6, pp. 1143-1149, 2009.

[11] X.-J. Ma, J.-M. Zhang, X.-X. Chang, B. Zheng, and M.-Y. Zhang, "Experimental study on creep of warm and ice-rich frozen soil," Chinese Journal of Geotechnical Engineering, vol. 29, no. 6, pp. 848-852, 2007.

[12] B. Zheng, J. M. Zhang, X. J. Ma et al., "Study on compression deformation of warm and ice-enriched frozen soil," Chinese Journal of Rock Mechanics and Engineering, vol. 28, supplement 1, pp. 3063-3068, 2009.

[13] Z. W. Wu, W. Ma, Y. B. Pu et al., "CT analysis on structure of frozen soil in creep process," CT Theory and Applications, vol. 4, no. 3, pp. 31-34, 1995.

[14] Y. Yang, Y. Lai, and X. Chang, "Experimental and theoretical studies on the creep behavior of warm ice-rich frozen sand," Cold Regions Science and Technology, vol. 63, no. 1-2, pp. 61-67, 2010.

[15] J. F. Zheng, Research on Meso-Structure Change of Frozen Soil under the Action of Load, Cold and Arid Regions Environmental 
and Engineering Research Institute of the Chinese Academy of Sciences, Lanzhou, China, 2009.

[16] X. R. Ge, Macromechanical and Micromechanical Experiment Research of Damage for Geomaterials, Science Press, 2004. 

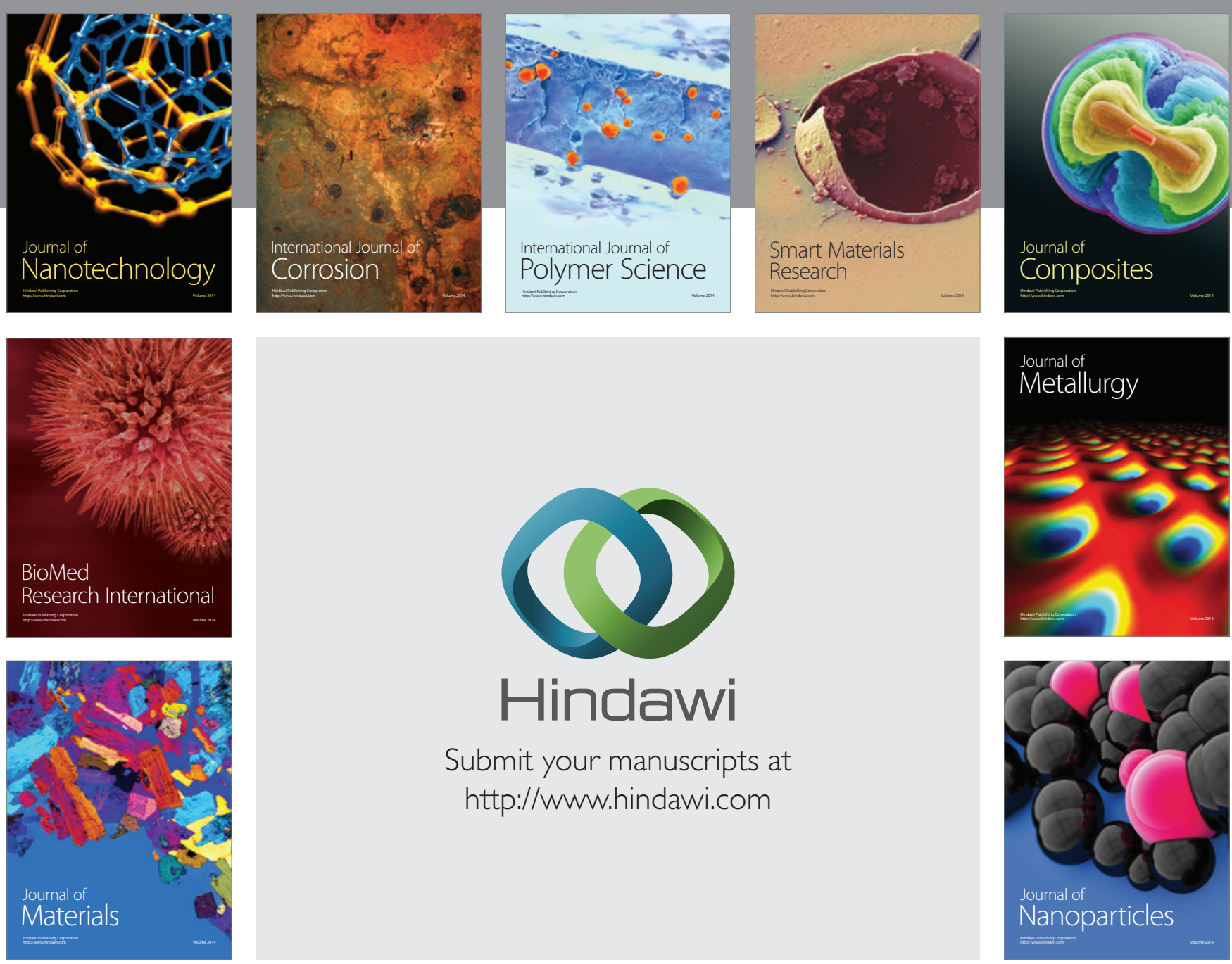

Submit your manuscripts at http://www.hindawi.com
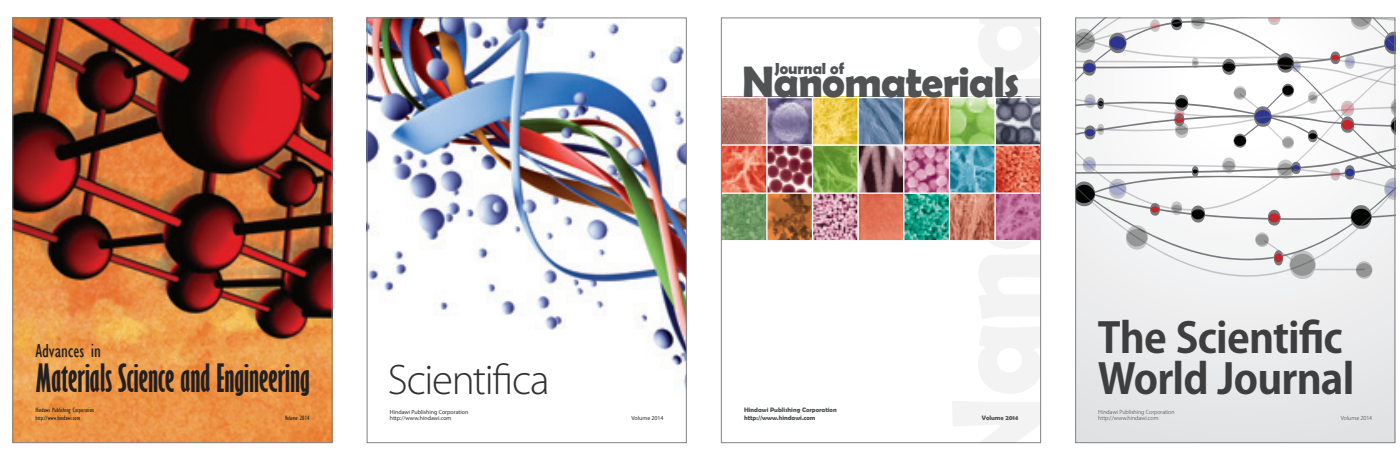

\section{The Scientific World Journal}
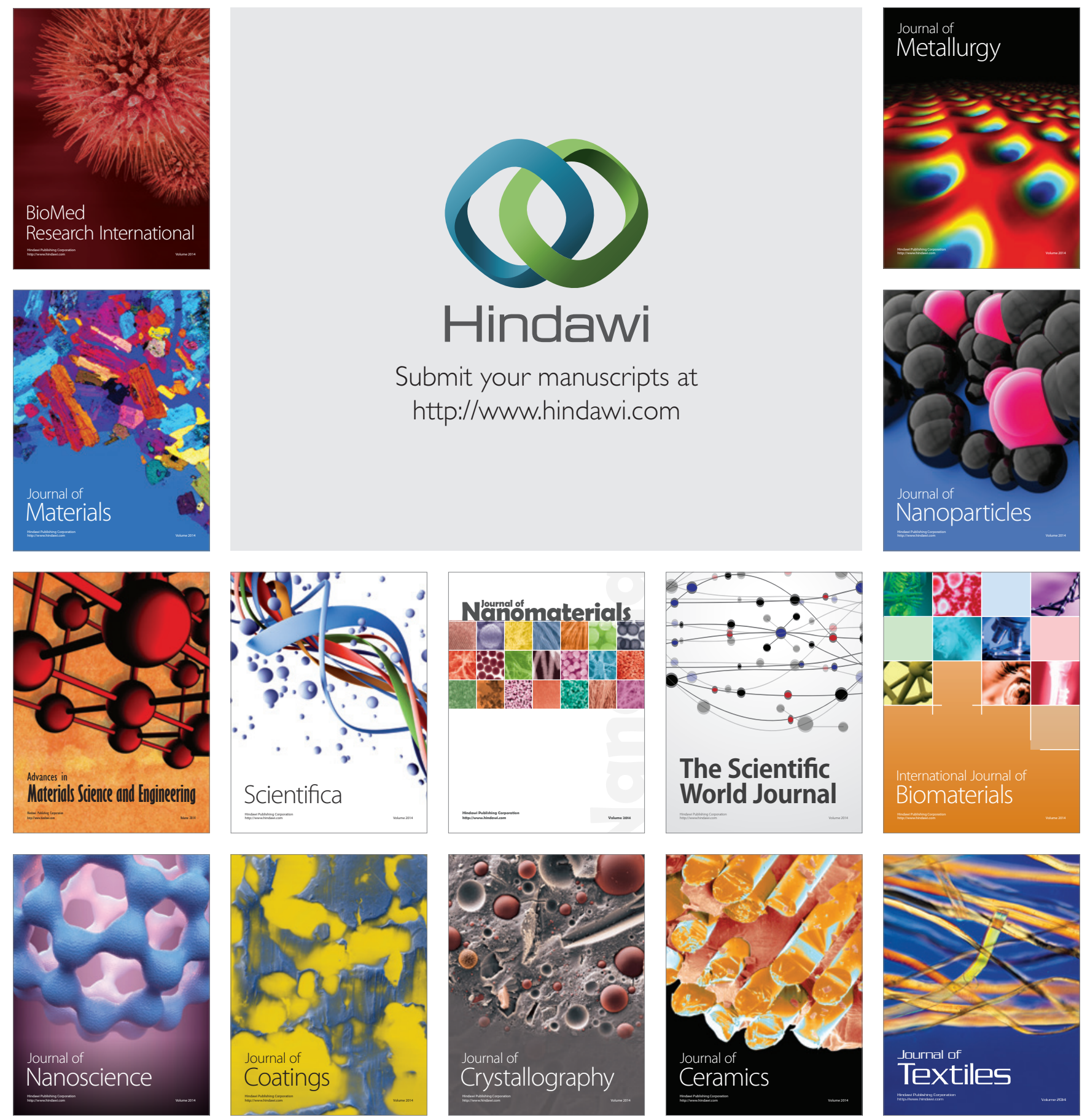